ARTICLE

https://doi.org/10.1038/s41467-020-14613-5

\title{
Mechanistic insight into carbon-carbon bond formation on cobalt under simulated Fischer- Tropsch synthesis conditions
}

\author{
C.J.(Kees-Jan) Weststrate (1) 1*, Devyani Sharma (1) 1,2, Daniel Garcia Rodriguez (1) 1,2, Michael A. Gleeson (1) 2, \\ Hans O.A. Fredriksson ${ }^{1} \&$ J.W.(Hans) Niemantsverdriet ${ }^{1,3}$
}

Facile $\mathrm{C}-\mathrm{C}$ bond formation is essential to the formation of long hydrocarbon chains in FischerTropsch synthesis. Various chain growth mechanisms have been proposed previously, but spectroscopic identification of surface intermediates involved in C-C bond formation is scarce. We here show that the high $\mathrm{CO}$ coverage typical of Fischer-Tropsch synthesis affects the reaction pathways of $\mathrm{C}_{2} \mathrm{H}_{x}$ adsorbates on a $\mathrm{Co}(0001)$ model catalyst and promote $\mathrm{C}-\mathrm{C}$ bond formation. In-situ high resolution $\mathrm{x}$-ray photoelectron spectroscopy shows that a high $\mathrm{CO}$ coverage promotes transformation of $\mathrm{C}_{2} \mathrm{H}_{\mathrm{x}}$ adsorbates into the ethylidyne form, which subsequently dimerizes to 2-butyne. The observed reaction sequence provides a mechanistic explanation for $\mathrm{CO}$-induced ethylene dimerization on supported cobalt catalysts. For Fischer-Tropsch synthesis we propose that $\mathrm{C}$ - $\mathrm{C}$ bond formation on the close-packed terraces of a cobalt nanoparticle occurs via methylidyne $(\mathrm{CH})$ insertion into long chain alkylidyne intermediates, the latter being stabilized by the high surface coverage under reaction conditions.

\footnotetext{
1'SynCat@DIFFER, Syngaschem BV, De Zaale 20, 5612 AJ Eindhoven, The Netherlands. ${ }^{2}$ Dutch Institute for Fundamental Energy Research (DIFFER), De Zaale 20, 5612 AJ Eindhoven, The Netherlands. ${ }^{3}$ SynCat@Beijing, Synfuels China Technology Co. Ltd., Leyuan South Street II, No. 1, Huairou District, 101407 Beijing, China. *email: c.j.weststrate@syngaschem.com
} 
S upported cobalt catalysts find their most widespread application in low-temperature Fischer-Tropsch synthesis (FTS), a process in which $\mathrm{C}-\mathrm{C}$ bond-forming reactions produce long-chain hydrocarbon products from synthesis gas, a mixture of $\mathrm{CO}$ and $\mathrm{H}_{2}{ }^{1}$. In today's fossil fuel-based economy, synthesis gas is predominantly manufactured from natural gas or coal, where FTS adds value by converting gaseous (gas-to-liquids) or solid (coal-to-liquids) reactants into more valuable products, such as food-grade wax, lubricants and sulfur-free transportation fuels. The FTS process will continue to play a role in future energy scenarios: synthesis gas can be derived from any carboncontaining source, e.g. biomass or even $\mathrm{CO}_{2}$ may be used ${ }^{2}$. These renewable carbon sources offer an alternative route to produce a 'syncrude' that can, to a large part, replace petroleum as the principal feedstock of chemicals and the liquid fuels that power transportation modes (airplanes, ships, heavy vehicles) that cannot be readily replaced by fully electric alternatives. Insight into the molecular mechanism by which long-chain hydrocarbon species grow on the surface of the cobalt catalyst particle is of direct relevance to better understand the molecular origin of selectivity in FTS and may ultimately drive rational design of catalysts.

A large variety of chain growth mechanisms can be found in the literature, summarized in, e.g. refs. ${ }^{3-5}$. Growth intermediates of different chain length co-exist on the active surface, and steady-state isotopic transient kinetic analysis studies reveal that their concentration is low ${ }^{6,7}$. Furthermore, they are surrounded by much larger quantities of co-adsorbates such as $\mathrm{C}_{1} \mathrm{H}_{\text {xad }}$ species ${ }^{8-10}, \mathrm{CO}_{\mathrm{ad}}{ }^{7,9,10}, \mathrm{H}_{\mathrm{ad}}{ }^{10}$ and long-chain products $^{11}$. This complexity makes it impossible to distinguish those few active surface species from other adsorbates by, e.g. in situ infrared (IR) absorption spectroscopy ${ }^{12}$. We instead use a model approach to study $\mathrm{C}_{x} \mathrm{H}_{y}$ reactivity on a cobalt catalyst under conditions relevant to FTS. As shown hereafter, it is important to study how co-adsorbed $\mathrm{H}_{\mathrm{ad}}$ and $\mathrm{CO}$ affect $\mathrm{C}_{x} \mathrm{H}_{y}$ reactivity, since both adsorbates will be present on the surface under reaction conditions.

Water is a major by-product of FTS, and the high conversion levels reached lead to a water partial pressure that amounts to several bars during industrial operation. However, since chain growth also occurs under low conversion conditions where the $\mathrm{H}_{2} \mathrm{O}$ partial pressure is low, the presence of $\mathrm{H}_{2} \mathrm{O}$ does not appear to be essential to the chain growth mechanism and therefore it was omitted from our study. Moreover, surface science studies show that water adsorbs much weaker on $\mathrm{Co}(0001)$ than on both $\mathrm{CO}$ and hydrogen ${ }^{13}$ and the $\mathrm{H}_{2} \mathrm{O}$ surface coverage under reaction conditions is expected to be low even when the $\mathrm{H}_{2} \mathrm{O}$ partial pressure is comparable to that of $\mathrm{CO}$ and $\mathrm{H}_{2}$. An in situ X-ray absorption study of cobalt supported on a carbon nanofiber support shows that neither bulk oxidation nor substantial surface oxidation occurs on cobalt during FTS $^{14}$. Furthermore, cobalt single crystals were found to be active for FTS ${ }^{11,15-18}$, and the turnover frequencies reported are similar to those found for supported catalysts. This confirms that metallic cobalt is the active phase for chain growth and that insights from single crystal studies are of direct relevance for fundamental understanding of FTS.

We here use a $\mathrm{Co}(0001)$ model catalyst to study how $\mathrm{C}_{2} \mathrm{H}_{x \mathrm{ad}}$ species react to form a new $\mathrm{C}$ - $\mathrm{C}$ bond under FTS-like conditions, that is, in the presence of co-adsorbed hydrogen and $\mathrm{CO}_{\mathrm{ad}}$. Using this approach, we find that $\mathrm{C}-\mathrm{C}$ bond formation is promoted by CO spectators, which stabilize the alkylidyne intermediate needed for this reaction. This finding can rationalize why $\mathrm{CO}$ promotes alkene dimerization on cobalt catalysts and reveals the hidden role of $\mathrm{CO}$ as promoter of chain growth during FTS on supported cobalt catalysts.

\section{Results}

$\mathrm{C}_{2} \mathrm{H}_{4}$ decomposition on $\mathrm{Co}(0001)$. Synchrotron-based highresolution X-ray photoemission spectroscopy (XPS) was used as the primary tool to determine both nature and concentration of the $\mathrm{C}_{x} \mathrm{H}_{y}$ surface intermediates that form at various stages in our experiments. The $\mathrm{C} 1 \mathrm{~s}$ binding energy is sensitive to both chemical nature and binding site of the carbon atom, and excitation of the $\mathrm{C}-\mathrm{H}$ stretch vibration along with the photoemission process gives rise to additional features at $+350-400 \mathrm{meV}\left(2800-3200 \mathrm{~cm}^{-1}\right)$ from the main photoemission peak ${ }^{19,20}$, with an intensity that is proportional to the number of hydrogen atoms attached to the carbon atom that is photo-ionized 19,20 .

Figure 1a shows high-resolution $\mathrm{C} 1 \mathrm{~s}$ spectra of the different surface intermediates that form during heating of an ethylenesaturated surface in vacuum, previously discussed in detail elsewhere ${ }^{21}$. The two peaks at 283.9 and $283.4 \mathrm{eV}$ in the spectrum at $100 \mathrm{~K}$ are attributed to the two carbon atoms of ethylene $e^{21,22}$. The changes seen around $180 \mathrm{~K}$ in the heat map of C1s spectra recorded during heating (Fig. 1b) are attributed to a combination of ethylene desorption and decomposition, the latter producing 0.12 monolayer $(\mathrm{ML})$ acetylene $\left(\mathrm{C}_{2} \mathrm{H}_{2 \mathrm{ad}}\right)+0.24 \mathrm{ML} \mathrm{H}_{\mathrm{ad}}$. The C1s spectrum of adsorbed acetylene shows a peak at $283.3 \mathrm{eV}$, which accounts for both carbon atoms and is accompanied by two small shoulders at +0.37 and $+0.74 \mathrm{eV}$ due excitation (double excitation) of the $\mathrm{C}-\mathrm{H}$ stretching vibration ${ }^{21-23}$. Acetylene remains stable up to $400 \mathrm{~K}$ where it dehydrogenates completely (see $\mathrm{H}_{2}$ desorption data reported below). Atomic carbon is the only adsorbate present after heating to $630 \mathrm{~K}$, as evident from the $\mathrm{C} 1 s$ peak at $282.8 \mathrm{eV}^{24}$

The influence of $\mathrm{CO}$ spectators on $\mathrm{C}_{2} \mathrm{H}_{x}$ reactivity. The mixed $\mathrm{C}_{2} \mathrm{H}_{2 \mathrm{ad}} / \mathrm{H}_{\mathrm{ad}}$ layer produced by heating the ethylene-covered surface to $220 \mathrm{~K}$ was chosen as the starting point to investigate how $\mathrm{CO}$ spectators affect $\mathrm{C}_{2} \mathrm{H}_{x \text { ad }}$ reactivity. A top view of the $\mathrm{C} 1 \mathrm{~s}$ spectra (Fig. 1c) shows that acetylene gets converted around $270 \mathrm{~K}$ when heated in the presence of $1 \times 10^{-7}$ mbar CO. A second reaction step is seen around $310 \mathrm{~K}$, while extensive dehydrogenation occurs above $350 \mathrm{~K}$ to produce a mixture of 'polymeric'24 $(284.4 \mathrm{eV})$ and atomic carbon $(282.7 \mathrm{eV})$ at $630 \mathrm{~K}$. This is different from the carbon layer found after heating in vacuum, which consisted exclusively of atomic carbon (Fig. 1a and Supplementary Note 1).

High-resolution C1s spectra reveal the identity of the intermediates formed at each stage. Figure $1 \mathrm{~d}$ only shows the spectral features due to the dominant product to simplify the discussion, while a detailed discussion of the as-measured spectra is provided in Supplementary Note 2. The spectrum recorded after heating to $200 \mathrm{~K}$ shows the spectral shape of acetylene, and co-adsorption of $\mathrm{CO}$ causes only a slight broadening of the acetylene peak. We find that up to $0.30 \mathrm{ML}$ CO can adsorb alongside the $0.12 \mathrm{ML}$ acetylene (and $0.24 \mathrm{ML} \mathrm{H}_{\mathrm{ad}}$ ), with $0.14 \mathrm{ML} \mathrm{CO}_{\mathrm{ad}}$ residing on top sites $\left(285.7 \mathrm{eV}^{25}\right)$ and $0.16 \mathrm{ML}$ in threefold hollow sites $\left(285.3 \mathrm{eV}^{25}\right)$.

Acetylene gets converted to ethylidyne between 220 and $270 \mathrm{~K}$, as evident from two new peaks at 282.9 and $283.5 \mathrm{eV}$ after heating to $285 \mathrm{~K}$. The peak at $282.9 \mathrm{eV}$ does not show any loss features related to the presence of $\mathrm{C}-\mathrm{H}$ bonds, in line with the assignment to the surface-bound carbon atom of ethylidyne $\left(\equiv \mathbf{C}-\mathrm{CH}_{3}\right)^{21,26}$. The three hydrogen atoms in the methyl group of ethylidyne give rise to prominent vibrational signals at +0.4 and $+0.8 \mathrm{eV}$ relative to the main peak at $283.5 \mathrm{eV}$. The $\mathrm{C} 1 \mathrm{~s}$ binding energy of the methyl group is $0.5 \mathrm{eV}$ lower than the typical value reported for methyl groups in a variety of other $\mathrm{C}_{x} \mathrm{H}_{y \text { ad }}$ adsorbates ${ }^{19,21,27}$. This can be attributed to the presence of $\mathrm{CO}_{\mathrm{ad}}$ : a similar downward shift of the methyl group binding energy of ethylidyne adsorbed 

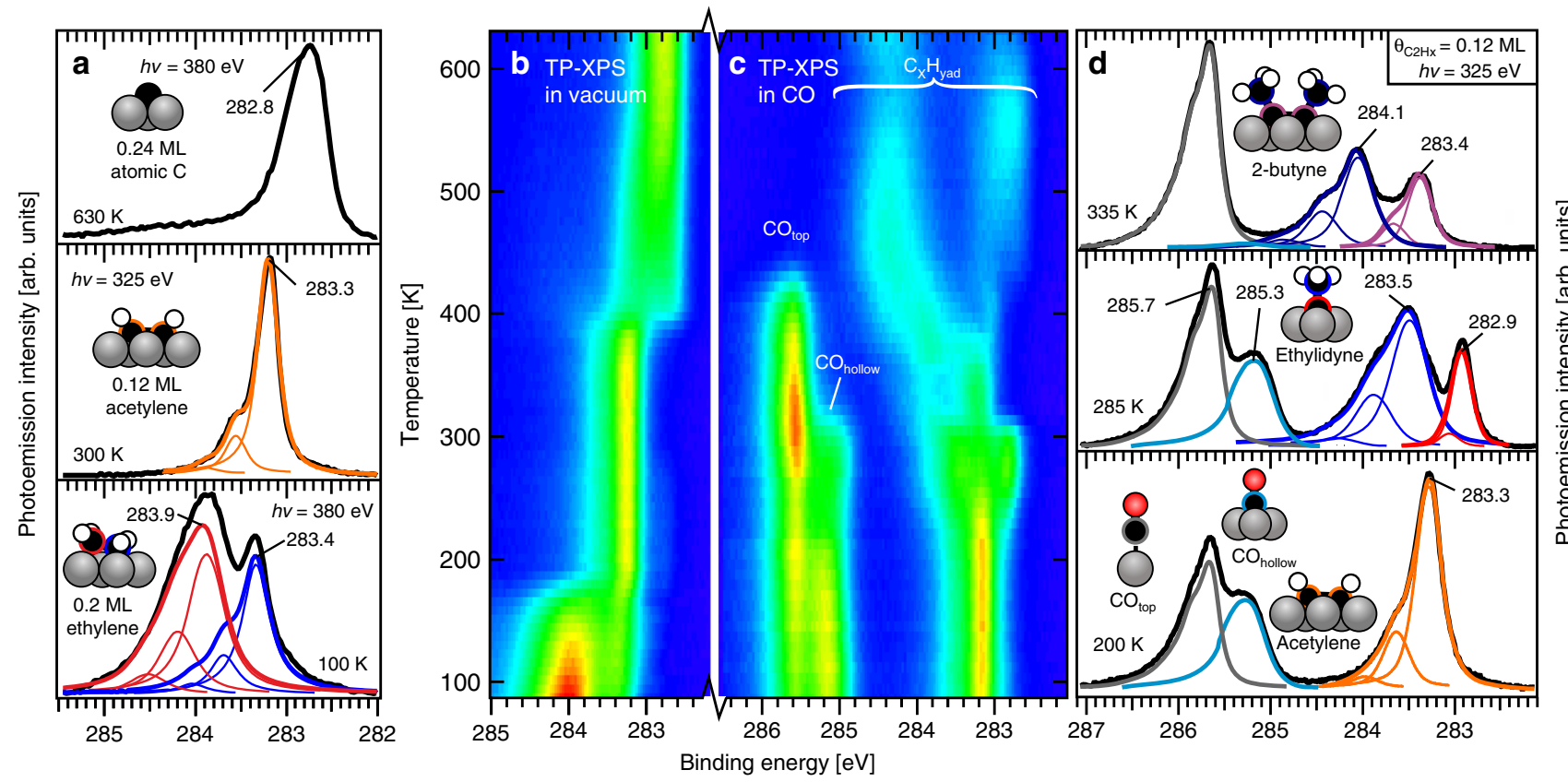

Fig. 1 C1s spectra of $\mathbf{C}_{\mathbf{x}} \mathbf{H}_{\mathbf{y}}$ adsorbates at different conditions. a High-resolution spectra after heating ethylene-saturated Co(0001) in vacuum to the indicated temperatures. $\mathbf{b}$ Heat map of $\mathrm{C} 1 \mathrm{~s}$ spectra recorded during heating of ethylene-covered $\mathrm{Co}(0001)$ in vacuum. $\mathbf{c}$ Heat map during heating of the $\mathrm{C}_{2} \mathrm{H}_{2 \mathrm{ad}} / 2 \mathrm{H}_{\text {ad }}$-covered surface in the presence of $1 \times 10^{-7} \mathrm{mbar} \mathrm{CO}(\mathrm{h} \nu=380 \mathrm{eV}, 7 \mathrm{~K}$ per spectrum, low intensity $=$ blue, high intensity $=$ red, heating rate $0.2 \mathrm{~K} \mathrm{~s}^{-1}$ ). d High-resolution spectra after heating $\mathrm{C}_{2} \mathrm{H}_{2 \mathrm{ad}} / 2 \mathrm{H}_{\mathrm{ad}}$ in $\mathrm{CO}$ to the temperatures indicated in the figure.

on $\mathrm{Rh}(111)$ upon co-adsorption of $\mathrm{CO}$ was reported previously ${ }^{26}$, and our reference experiment (Supplementary Note 3) showed that co-adsorption of $\mathrm{CO}$ alongside adsorbed propyne causes a $\mathrm{CO}$ coverage-dependent shift of the methyl $\left(\mathrm{H}_{3} \mathrm{C}-\mathrm{C} \equiv \mathrm{CH}\right)$ binding energy, from $284 \mathrm{eV}$ down to $283.5 \mathrm{eV}$ for the highest $\mathrm{CO}$ coverage. The CO coverage at this point is $0.30 \mathrm{ML}$ but now with $0.18 \mathrm{ML}$ CO adsorbed on-top and 0.12 ML in hollow sites.

Two ethylidyne adsorbates couple around $310 \mathrm{~K}$ to form a 2-butyne product. This proposition is confirmed by the highresolution spectrum recorded after heating to $335 \mathrm{~K}$, which closely resembles the previously reported high-resolution spectrum of 2-butyne adsorbed on $\mathrm{Ni}(111)^{28}$. The $\mathrm{CO}$ coverage has dropped to $0.21 \mathrm{ML}$, and only the top sites are populated at this point. Reference experiments using propyne (Supplementary Note 3$)^{21}$ show that $\mathrm{CO}_{\text {top }}$ has only a minor influence on the methyl binding energy, and both methyl groups in 2-butyne, $\mathrm{H}_{3} \mathbf{C}-\mathrm{C} \equiv \mathrm{C}-\mathrm{CH}_{3}$, therefore appear at $284.1 \mathrm{eV}$, the typical value for - $\overline{\mathrm{C}}_{3}{ }_{3}^{19,21,27}$. The $283.4 \mathrm{eV}$ peak is attributed to the two central carbon atoms of adsorbed 2-butyne, $\mathrm{H}_{3} \mathrm{C}-\mathrm{C} \equiv \mathrm{C}-\mathrm{CH}_{3}$. Their binding energy value is identical to that of the central carbon atom of adsorbed propyne $\mathrm{H}_{3} \mathrm{C}-\underline{\mathrm{C}} \equiv \mathrm{CH}$, which is unsurprising since the adsorption site and immediate surroundings of the central carbon atoms in adsorbed propyne and 2-butyne are practically identical.

These results thus show that CO spectators cause acetylene to react with surface hydrogen to produce ethylidyne around $270 \mathrm{~K}$. Two ethylidyne products subsequently couple around $310 \mathrm{~K}$ to produce adsorbed 2-butyne. Other experimental techniques corroborate these conclusions and reveal additional details. Temperature-programmed reaction spectroscopy (TRPS; Fig. 2a) shows that $\sim 0.08 \mathrm{ML}$ ethylene desorbs intact during heating of the ethylene-saturated surface in vacuum. Hydrogen desorbs in two steps, with a peak at $320 \mathrm{~K}$ due to recombination of the 0.24 $\mathrm{ML} \mathrm{H}_{\mathrm{ad}}$ produced by ethylene decomposition to acetylene and another peak around $400 \mathrm{~K}$, which amounts to $0.24 \mathrm{ML} \mathrm{H}_{2}$ and is attributed to complete dehydrogenation of acetylene ${ }^{21,29}$. The presence of CO strongly affects the $\mathrm{H}_{2}$ TPRS trace as shown in

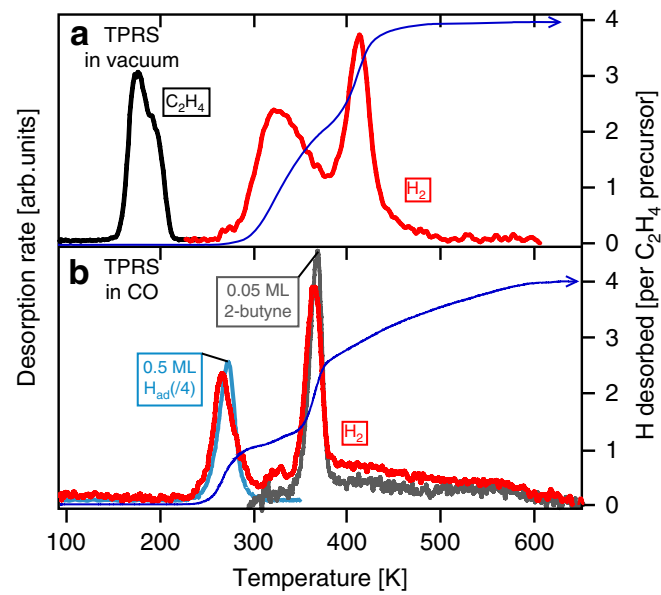

Fig. 2 Temperature-programmed reaction spectroscopy. Ethylene (black line) and hydrogen desorption (red line) during heating $\left(0.2 \mathrm{~K} \mathrm{~s}^{-1}\right)$ of $\mathbf{a}$ an ethylene-saturated $\mathrm{Co}(0001)$ in vacuum and $\mathbf{b}$ a $0.12 \mathrm{ML} \mathrm{C}_{2} \mathrm{H}_{2 \mathrm{ad}} / 0.24 \mathrm{ML}$ $\mathrm{H}_{\mathrm{ad}}$-covered surface in $1 \times 10^{-7}$ mbar $\mathrm{CO} . \mathrm{H}_{2}$ desorption from a $0.5 \mathrm{ML}$ $\mathrm{H}_{\mathrm{ad}}$-covered surface heated in $\mathrm{CO}$ (light blue and divided by 4 to facilitate comparison) and $\mathrm{H}_{2}$ desorption due to 2-butyne decomposition (grey line, in $1 \times 10^{-7} \mathrm{mbar} \mathrm{CO}$ ) are added for reference. The dark blue lines show the integral of the $\mathrm{H}_{2}$ desorption traces in the absence and presence of $\mathrm{CO}$, normalized to the number of $\mathrm{H}$ atoms in the ethylene precursor.

Fig. 2b. The peak around $270 \mathrm{~K}$ is attributed to desorption of surface-bound hydrogen, shifted downward due to the presence of $\mathrm{CO}^{30-32}$. The peak area indicates that $0.12 \mathrm{ML} \mathrm{H}_{\mathrm{ad}}$ desorbs around $270 \mathrm{~K}$, only $50 \%$ of the $0.24 \mathrm{ML} \mathrm{H}_{\mathrm{ad}}$ that was present prior to $\mathrm{CO}$ exposure. This is explained by acetylene hydrogenation to ethylidyne $\left(\mathrm{HC} \equiv \mathrm{CH}+\mathrm{H}_{\mathrm{ad}} \rightarrow \equiv \mathrm{C}-\mathrm{CH}_{3}\right)$, a reaction that consumes one $\mathrm{H}_{\mathrm{ad}}$ for each acetylene adsorbate converted. The $\mathrm{H}_{2}$ desorption trace above $320 \mathrm{~K}$ has a close similarity to that of a reference experiment in which $0.05 \mathrm{ML}$ 2-butyne was heated in the presence of CO. This supports the conclusion that adsorbed 

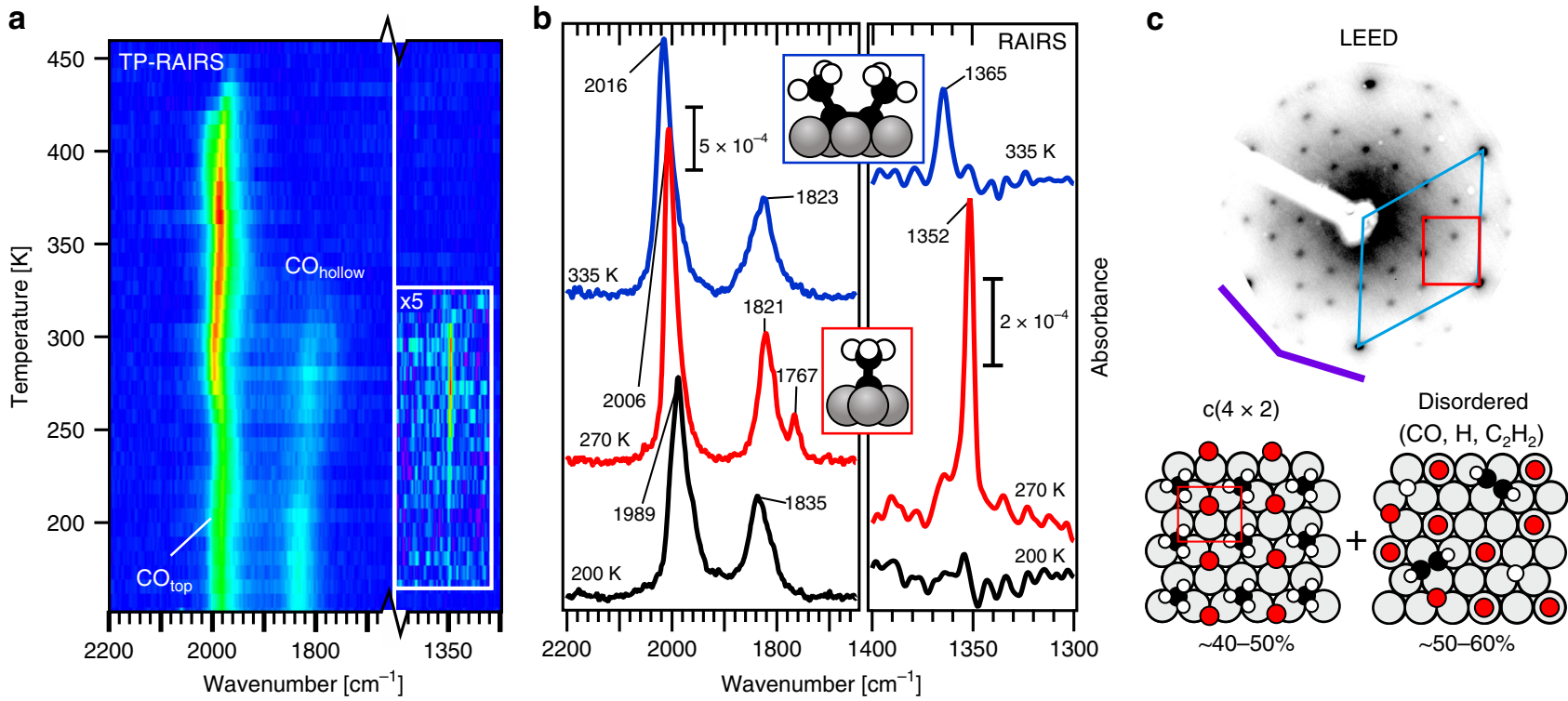

Fig. 3 IR absorption spectroscopy and electron diffraction. a TP-RAIRS ( $8 \mathrm{~K}$ per spectrum, low absorbance $=$ blue, high absorbance $=$ red) and $\mathbf{b}$ IR absorption spectra $\left(T_{\text {sample }}=90 \mathrm{~K}\right.$ ) during heating of $\mathrm{C}_{2} \mathrm{H}_{2 \mathrm{ad}} / 2 \mathrm{H}_{\mathrm{ad}}$ adsorbed on $\mathrm{Co}(0001)$ in $\mathrm{CO}$. The symmetric methyl bending mode $\left(1352 \mathrm{~cm}^{-1}\right)$ indicate that ethylidyne is present between 250 and $300 \mathrm{~K}$. c LEED $(80 \mathrm{eV})$ shows a c $(4 \times 2)$ pattern between 270 and $305 \mathrm{~K}$, attributed to islands of an ordered ethylidyne/CO layer that cover up to $50 \%$ of the surface $\left(p_{\mathrm{CO}}=1 \times 10^{-7} \mathrm{mbar}\right.$, heating rate $0.2 \mathrm{~K} \mathrm{~s}^{-1}, \theta_{\mathrm{C} 2 \mathrm{Hx}}=0.12 \mathrm{ML}$ ).

2-butyne is produced by subsequent ethylidyne coupling (Supplementary Note 4). We attribute the pronounced peak at $370 \mathrm{~K}$ to dehydrogenation of the two methyl groups in 2butyne $^{21}$. The remaining hydrogen gradually leaves the surface between 380 and $600 \mathrm{~K}$, characteristic of dehydrogenation of 'polymeric' surface carbon, the formation of which was also evident from XPS. The small $\mathrm{H}_{2}$ desorption peak around $320 \mathrm{~K}$ is attributed to a minor quantity of ethylidyne that did not find a coupling partner and instead dehydrogenate back to acetylene.

Figure $3 \mathrm{a}$ shows the top view of a series of reflection absorption infrared spectra (RAIRS), recorded during heating of an $\mathrm{C}_{2} \mathrm{H}_{2 \mathrm{ad}} / 2$ $\mathrm{H}_{\mathrm{ad}}$-covered surface in CO. Individual high-quality spectra at the temperatures indicated are shown in Fig. 3b. The strong bands around 2000 and $1840 \mathrm{~cm}^{-1}$ are due to $\mathrm{CO}_{\text {top }}$ and $\mathrm{CO}_{\text {hollow, }}$ respectively ${ }^{25}$. $\mathrm{CO}$ adsorbed alongside small $\mathrm{C}_{x} \mathrm{H}_{y}$ adsorbates attenuates absorption bands in the $\mathrm{C}-\mathrm{H}\left(\sim 2800-3000 \mathrm{~cm}^{-1}\right)$ and C-C (1000-1200 $\left.\mathrm{cm}^{-1}\right)$ stretching regions, a phenomenon that has been observed before for ethylidyne adsorbed alongside $\mathrm{CO}$ on, e.g. $\mathrm{Ru}(0001)$ and $\mathrm{Pt}(111)^{32-34}$. This leaves only the $\mathrm{C}-\mathrm{H}$ bending region $\left(1500-1300 \mathrm{~cm}^{-1}\right)$ as our main source of information. The $1352 \mathrm{~cm}^{-1}$ band, which appears around $220 \mathrm{~K}$ and disappears again around $300 \mathrm{~K}$, can be readily assigned to the symmetric bending mode $\left(\delta_{\mathrm{s}}-\mathrm{CH}_{3}\right)$ of ethylidyne ${ }^{35}$. The band at $1767 \mathrm{~cm}^{-1}$ that appears and disappears together with the $1352 \mathrm{~cm}^{-1}$ band has been reported previously for $\mathrm{CO}_{\text {hollow }}$ co-adsorbed with ethylidyne on both $\mathrm{Rh}(111)$ and $\mathrm{Ru}(0001)^{34,36}$.

The ethylidyne product forms an ordered adsorbate overlayer together with $\mathrm{CO}$, as evident from the $\mathrm{c}(4 \times 2)$ diffraction pattern that was found between 270 and $305 \mathrm{~K}$ by low-energy electron diffraction (LEED) (Fig. 3c). The ordered ethylidyne/CO $\mathrm{CO}_{\text {hollow }}$ overlayer that causes this pattern is known from earlier studies on $\mathrm{Rh}(111)^{26,36}$. The local ethylidyne coverage in the $\mathrm{c}(4 \times 2)$ structure is $0.25 \mathrm{ML}$. However, the overall $\mathrm{C}_{2} \mathrm{H}_{\text {xad }}$ coverage in our experiment is only $0.12 \mathrm{ML}$. This means that the $\mathrm{c}(4 \times 2)$ pattern is caused by islands of ethylidyne/ $\mathrm{CO}_{\text {hollow }}$ that cover only $40-50 \%$ of the surface, leaving the other half covered by a disordered layer, which contains $\mathrm{CO}$ as well as minor quantities of unreacted acetylene and $\mathrm{H}_{\mathrm{ad}}$. A more detailed analysis of this structure is provided in Supplementary Note 5 . The $c(4 \times 2)$ pattern disappears above $300 \mathrm{~K}$, and the IR absorption spectrum after heating to $335 \mathrm{~K}$ shows a weak band at $1365 \mathrm{~cm}^{-1}$. This is attributed to the $\delta_{\mathrm{s}}-\mathrm{CH}_{3}$ mode of adsorbed 2-butyne, an assignment that is supported by reference spectra using 2butyne (Supplementary Note 4 ).

XPS at near-ambient pressure (NAP). The reactivity of acetylene under high-coverage conditions was further explored using the HIPPIE beamline of MAX IV, which allows XPS measurements at near-ambient pressures. Figure 4 shows a series of $\mathrm{C} 1 \mathrm{~s}$ spectra recorded during an isothermal experiment at $313 \mathrm{~K}$ in which a $0.08 \mathrm{ML}$ acetylene-covered $\mathrm{Co}(0001)$ surface (prepared by dosing ethylene at $313 \mathrm{~K}$ ) was exposed to an increasingly high $\mathrm{H}_{2}$ pressure. $\mathrm{A} \mathrm{H}_{2}$ pressure of $\sim 10^{-5}$ mbar would be sufficient to create a high hydrogen coverage at $313 \mathrm{~K}^{31,37}$, but the spectrum shape shows that co-adsorbed hydrogen did not cause the acetylene to react.

A CO contamination in the gas led to the appearance of $\mathrm{CO}_{\mathrm{ad}}$ when the hydrogen pressure was increased to $1 \times 10^{-2} \mathrm{mbar}$. The appearance of $\mathrm{CO}_{\mathrm{ad}}$ coincides with the conversion of acetylene to ethylidyne, the temporary formation of the latter being evident from the transient peaks at 282.9 and $283.8 \mathrm{eV}$. The $\mathrm{CO}_{\text {hollow }}$ peak $(285.2 \mathrm{eV})$ comes and goes together with the ethylidyne-related peaks, consistent with the RAIRS results which show that $\mathrm{CO}_{\text {hollow }}$ is associated with ethylidyne. Ethylidyne reacts further to produce 2-butyne, evident from a peak at $283.4 \mathrm{eV}$ due to the two central carbon atoms and at $284.1 \mathrm{eV}$ due to the two methyl groups. Acetylene conversion reached completion after $400 \mathrm{~s}$ in $1 \times 10^{-2} \mathrm{mbar}_{2}$, and a pressure increase to $1 \times 10^{-1} \mathrm{mbar}_{2}$ did not affect 2-butyne at all. Interestingly, this pressure increase triggers the desorption of $\mathrm{CO}_{\mathrm{ad}}$. We attribute this to the same repulsive interactions that cause the decreased $\mathrm{H}_{2}$ desorption temperature when $\mathrm{H}_{\mathrm{ad}}$ is heated in $\mathrm{CO}$ (Fig. 2b). With an overwhelming majority of hydrogen in the NAP experiment, $\mathrm{H}_{\mathrm{ad}^{-}}$ induced destabilization of $\mathrm{CO}_{\mathrm{ad}}$ causes it to desorb at $313 \mathrm{~K}$, significantly below its 'normal' desorption temperature of $350-400 \mathrm{~K}^{25}$.

The invariance of the $\mathrm{C} 1 \mathrm{~s}$ spectral shape during subsequent heating in $1 \times 10^{-1} \mathrm{mbar}_{2}$ (Fig. 5) indicates that 2-butyne 


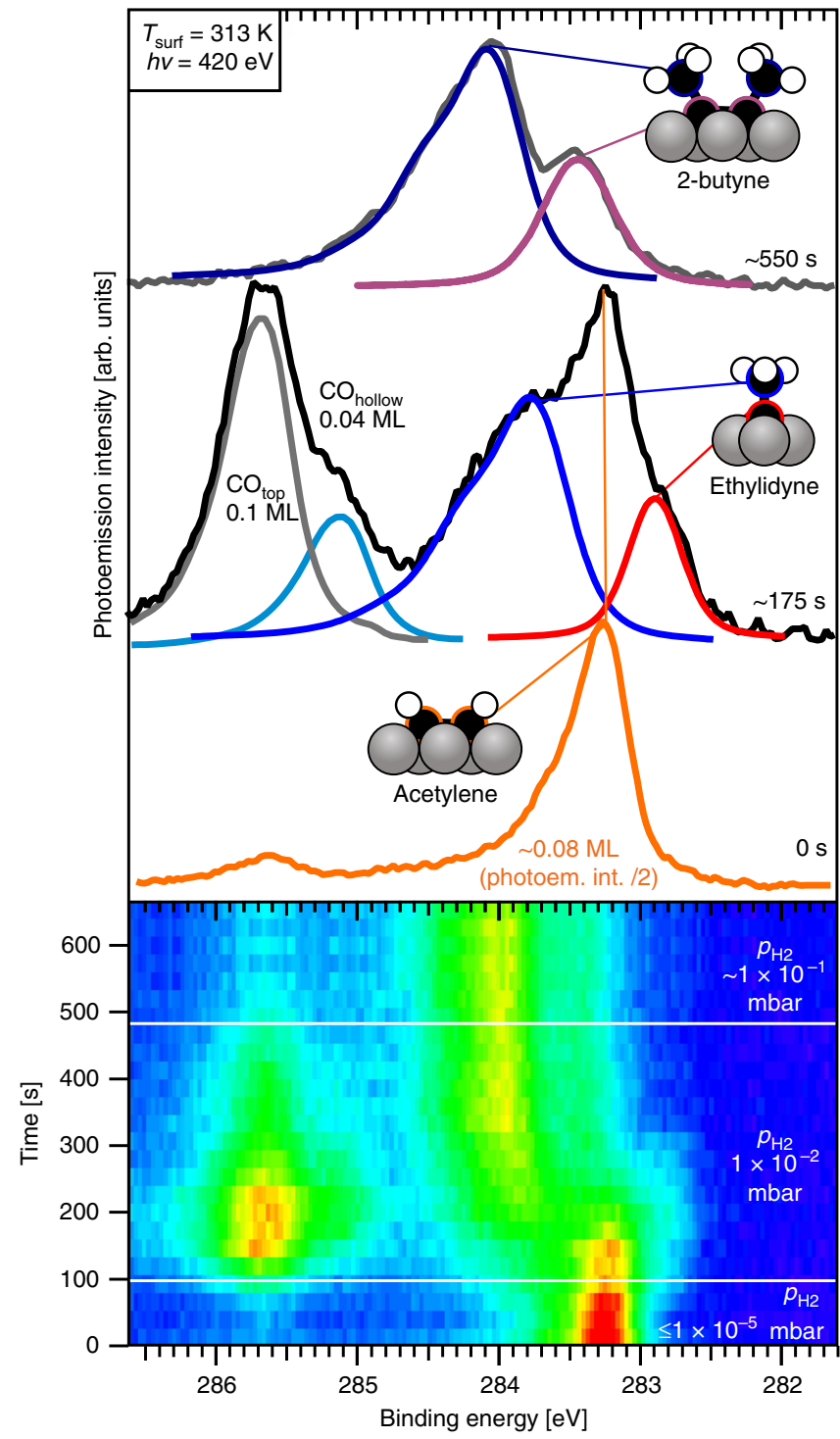

Fig. 4 XPS at near-ambient pressures. C1s spectra recorded during exposure of an acetylene-covered $\mathrm{Co}(0001)$ surface to increasingly high $\mathrm{H}_{2}$ pressures at $T=313 \mathrm{~K}$. The time evolution of the C1s spectra is shown in the lower panel, whereas the top view shows the spectra at specific stages of the experiment $(h \nu=420 \mathrm{eV})$. Note that the signal intensity of the acetylene spectrum in the upper panel was divided by two to facilitate comparison.

remains intact during heating. The decrease of the signal intensity $>370 \mathrm{~K}$ is attributed to loss of 2-butyne from the surface. Since computed alkyne adsorption energies are in excess of $200 \mathrm{~kJ} \mathrm{~mol}^{-1}$, the possibility that 2-butyne simply desorbs can be excluded ${ }^{38}$. We instead propose that 2-butyne is hydrogenated to 2-butene, which desorbs upon formation. A simple kinetic analysis (Supplementary Note 6) yields an apparent activation energy of $106 \pm 12 \mathrm{~kJ} \mathrm{~mol}^{-1}$ for 2-butyne hydrogenation.

\section{Discussion}

The results presented here provide uniquely detailed information on the mechanism by which $\mathrm{C}-\mathrm{C}$ bonds are formed between two $\mathrm{C}_{x} \mathrm{H}_{y}$ species adsorbed on a $\mathrm{Co}(0001)$ model catalyst in the presence of co-adsorbed $\mathrm{CO}$ and $\mathrm{H}_{\mathrm{ad}}$. After discussing the barriers for ethylidyne formation and ethylidyne dimerization and the possible origins of the driving force of these reactions, we

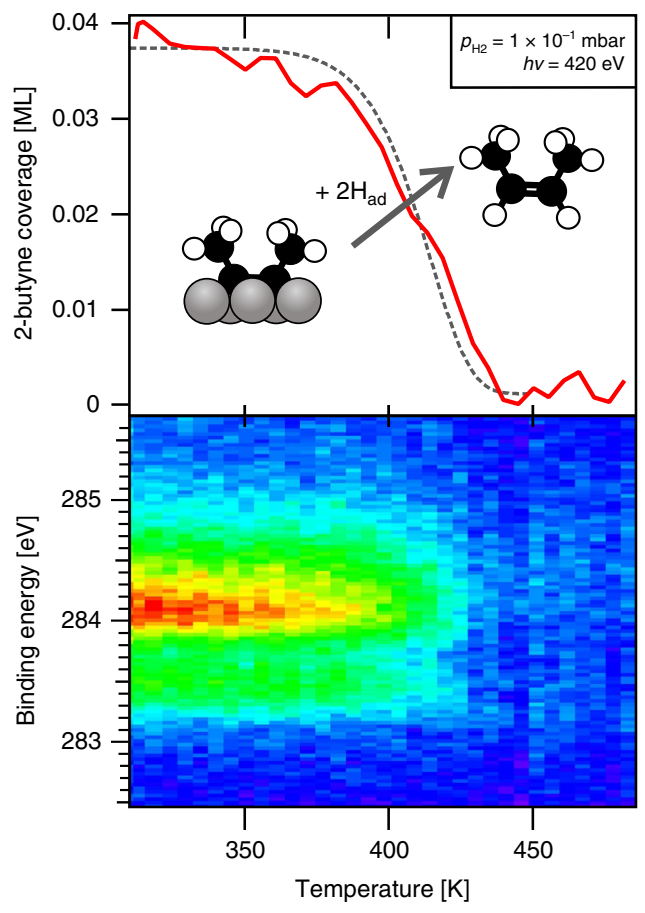

Fig. 5 XPS during heating in a hydrogen atmosphere. Peak area and top view of the $\mathrm{C} 1 \mathrm{~s}$ spectra recorded during heating of ( $0.04 \mathrm{ML})$ 2-butynecovered $\mathrm{Co}(0001)$ in the presence of $1 \times 10^{-1} \mathrm{mbar} \mathrm{H}_{2}\left(0.2 \mathrm{~K} \mathrm{~s}^{-1}, \mathrm{h \nu}=420\right.$ $\mathrm{eV}$ ). The experimental data is shown by a solid red line, while the output of our kinetic model is shown as a dashed grey line.

continue with a discussion of how these findings relate to C-C bond formation reactions catalysed by metallic cobalt in the presence of $\mathrm{CO}$.

Quantitative analysis of the TP-XPS data (Supplementary Note 5) yields the coverage of all C-containing adsorbates during the CO-induced reaction while $\theta_{\mathrm{H}}$ can be deduced from the $\mathrm{H}_{2}$ desorption trace. Figure 6 shows the adsorbate coverages together with the output of a simple mean field microkinetic model (Supplementary Note 6) used to estimate reaction barriers for acetylene hydrogenation and ethylidyne dimerization. The conversion of acetylene to ethylidyne requires the addition of two hydrogen atoms to one end of the molecule and abstraction of a hydrogen atom from the other end. Our analysis yields an overall barrier height of only $60 \pm 6 \mathrm{~kJ} \mathrm{~mol}^{-1}$, far below the computed barriers $>100 \mathrm{~kJ} \mathrm{~mol}^{-1}$ as predicted by density functional theory starting with either acetylene hydrogenation or acetylene dehydrogenation as a first step ${ }^{39-41}$. This indicates that the high CO coverage may also lower the reaction barriers involved in the conversion of acetylene.

Acetylene is the most stable $\mathrm{C}_{2} \mathrm{H}_{x}$ adsorbate in the absence of $\mathrm{CO}^{21,38-41}$, and it is therefore the sole product of ethene decomposition around $180 \mathrm{~K}$. The experiments show that CO causes conversion of acetylene to ethylidyne, and the driving force for this must be that ethylidyne becomes more stable than acetylene when $\mathrm{CO}$ is present on the surface ${ }^{32,40}$. Two experimental observations give more insight into why ethylidyne is preferred when $\mathrm{CO}$ is present: (i) repulsive interactions between $\mathrm{H}_{\mathrm{ad}}$ and $\mathrm{CO}_{\mathrm{ad}}$ destabilize $\mathrm{H}_{\mathrm{ad}}$ (Fig. 2b), thereby destabilizing one of the reactants. (ii) The formation of ordered $\mathrm{CO}_{\text {hollow/ }}$ ethylidyne layer islands with a local high coverage is driven by attractive interactions, indicating that the ethylidyne reaction product is stabilized by $\mathrm{CO}_{\mathrm{ad}}$ (Fig. 3c). Mate et al. ${ }^{42}$ attributed the ordering of mixed ethylidyne/CO layers on $\mathrm{Rh}(111)$ to favourable dipole-dipole interactions due to the oppositely oriented dipoles 


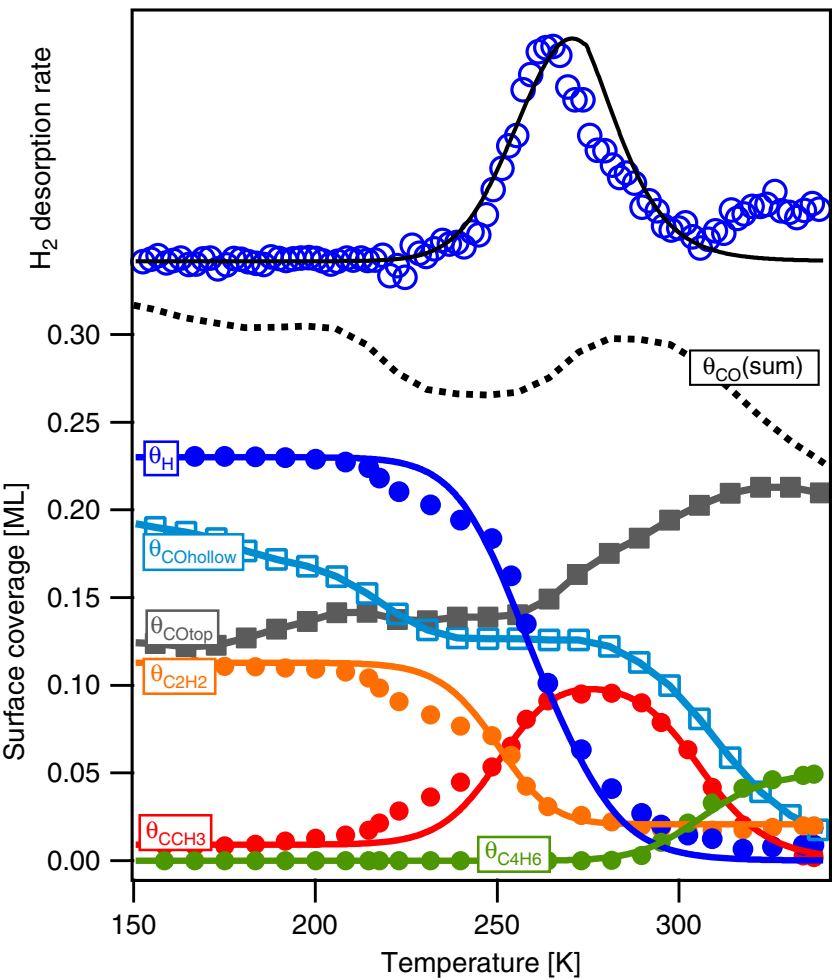

Fig. 6 Surface coverage during heating in CO. Markers show the surface coverages obtained from analysis of TP-XPS and TPRS during heating of a $\mathrm{C}_{2} \mathrm{H}_{2 \mathrm{ad}} / 2 \mathrm{H}_{\text {ad }}$-covered $\mathrm{Co}(0001)$ surface in $1 \times 10^{-7} \mathrm{mbar} \mathrm{CO}\left(0.2 \mathrm{~K} \mathrm{~s}^{-1}\right)$.

The output of a mean field microkinetic model is provided by the solid lines. The measured and simulated hydrogen desorption spectrum is added for comparison.

of $\mathrm{CO}$ and ethylidyne. A third contributing factor is that a high surface coverage favours species that occupy less space on the surface $^{21}$. This makes acetylene hydrogenation to ethylidyne favourable, first because it incorporates a surface hydrogen into the $\mathrm{C}_{x} \mathrm{H}_{y}$ adsorbate, and second, the footprint of ethylidyne is expected to be lower than that of acetylene since the former adsorbs through only one carbon atom.

Earlier studies have shown that methylidyne dimerizes around $250 \mathrm{~K}$ on both $\mathrm{Ni}(111)$ and $\mathrm{Co}(0001)$ to form acetylene $\mathrm{e}^{31,43,44}$. We here show that ethylidyne, the methyl-substituted analogue of methylidyne, reacts in a similar way to produce 2-butyne. We attribute the comparatively higher temperature ( 310 vs $250 \mathrm{~K}$ ) to increased steric hindrance in the transition state for coupling when hydrogen is replaced by a bulky methyl group. Ethylidyne reactivity in the absence of $\mathrm{CO}$ was studied by intentionally maximizing beam-induced ethylene decomposition (Supplementary Note 7). Instead of dimerization, we find that ethylidyne dehydrogenates to acetylene around $280 \mathrm{~K}$ during heating in vacuum ${ }^{21}$. Since dimerization of $\mathrm{CH}_{\mathrm{ad}}$ does not require $\mathrm{CO}$ to be present, we propose that $\mathrm{CO}_{\mathrm{ad}}$ is not needed for the $\mathrm{C}-\mathrm{C}$ bond formation reaction itself. Instead, $\mathrm{CO}$ facilitates the $\mathrm{C}-\mathrm{C}$ bondforming reaction indirectly: it stabilizes ethylidyne so that it still exists at $310 \mathrm{~K}$ in our temperature-programmed experiment, the temperature required to overcome the barrier of $75 \pm 7 \mathrm{~kJ} \mathrm{~mol}^{-1}$ associated with ethylidyne dimerization.

The work of Eidus et al. ${ }^{45}$ shows that traces of CO during ethylene hydrogenation on a supported cobalt catalyst changes the product selectivity, from ethane to $\mathrm{C}_{4}$ products. Cant et al. ${ }^{46}$ reproduced these early studies and reported cis-2-butene as the main $\mathrm{C}_{4}$ product of ethylene hydrogenation at $393 \mathrm{~K}$ in presence of CO. CO-induced stabilization of ethylidyne is key to

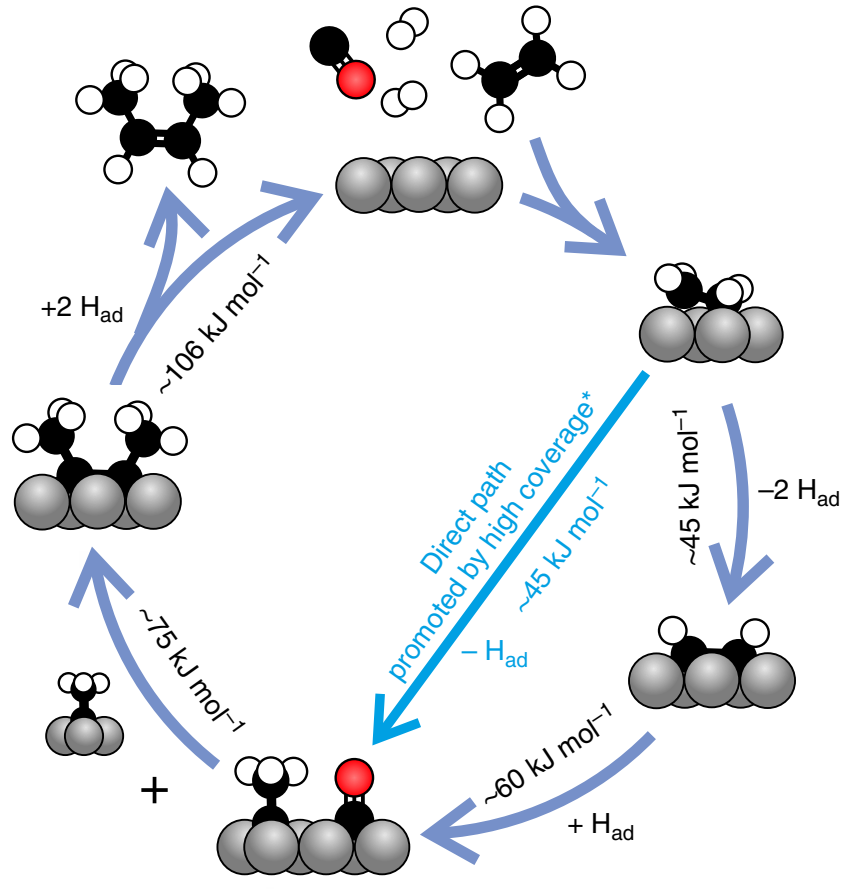

Fig. 7 Proposed catalytic cycle of CO-induced ethylene dimerization. The proposal is based on the experimental findings on $\mathrm{Co}(0001)$ presented here and in ref. ${ }^{21^{*}}$

understand why CO promotes ethylene dimerization on cobalt. Figure 7 shows the proposed catalytic cycle for this reaction, with activation energies derived from direct observation of the respective reactions on our single-crystal model catalyst. Ethylene decomposition initially produces acetylene, which is quickly hydrogenated to ethylidyne under the influence of CO spectators. Alternatively, a more direct pathway may exist from ethylene to ethylidyne: our previous work shows that ethylidyne can also form directly as a minor product of ethylene decomposition around $180 \mathrm{~K}$, but only when the surface is highly covered by $\mathrm{C}_{x} \mathrm{H}_{y \text { ad }}$ and/or $\mathrm{H}_{\mathrm{ad}}{ }^{21}$. The $\mathrm{C}-\mathrm{C}$ bond is then formed via coupling of two ethylidynes. Hydrogenation of the alkyne coupling product is the slowest step, and the 2-butyne concentration under reaction conditions is therefore expected to be rather high. This facilitates the formation of carbonaceous deposits via side reactions such as 2-butyne dehydrogenation and alkyne cyclo-trimerization ${ }^{38,47}$, and explains the fast catalyst deactivation which was attributed to carbon deposition by Cant et al. ${ }^{46}$.

The surface composition during CO-promoted ethylene dimerization is similar to the situation during FTS, as in both cases hydrocarbon surface intermediates react to form new C-C bonds on a cobalt surface covered with $\mathrm{CO}$ and surface hydrogen. For FTS, Bezemer et al. ${ }^{14}$ report a CO turnover frequency of only $2.3 \times 10^{-2} \mathrm{~s}^{-1}$ for their most active cobalt catalyst (tested at $483 \mathrm{~K}$ and 35 bar). This translates to a production rate of only 40 monomers per second on each cobalt crystallite (hemispherical, average diameter $8.5 \mathrm{~nm}$ ). So even in the unlikely case that all monomers insert into a single chain, it still takes $\sim 0.25 \mathrm{~s}$ to grow a one $\mathrm{C}_{10}$ product molecule per particle $\left(\mathrm{C}_{10}\right.$ being the average chain length when $\left.\alpha=0.9^{4}\right)$. Such slow growth on the second time scale can only involve very stable growth intermediates that have difficulty leaving the surface. Our work shows that alkynes and alkylidynes are indeed very stable, and the NAP-XPS experiment (Fig. 5) confirms that alkyne hydrogenation is a slow reaction that only proceeds at a significant rate above $370 \mathrm{~K}$. Their high stability and long lifetimes thus make alkynes and 


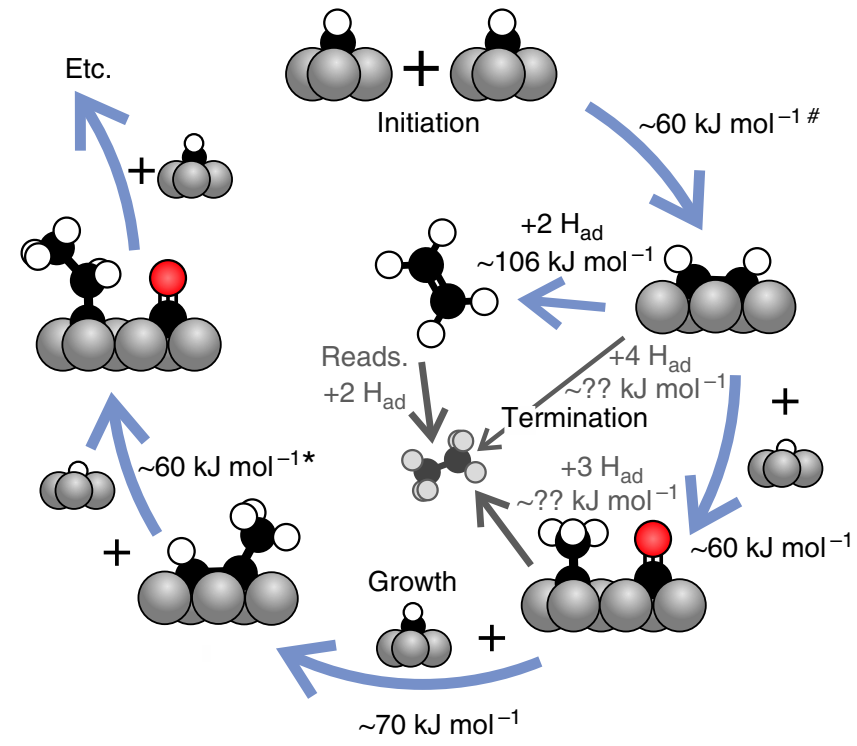

Fig. 8 Proposed chain growth mechanism on close-packed terraces. Steps depicted in colour were either observed directly or derived from direct observation of analogue reactions. The barrier for $\mathrm{CH}+\mathrm{CCH}_{2} \mathrm{R}$ is proposed to be between the $60 \mathrm{~kJ} \mathrm{~mol}^{-1}$ reported for $\mathrm{CH}$ dimerization4,31,43,44\# and $75 \mathrm{~kJ} \mathrm{~mol}^{-1}$ for ethylidyne dimerization. Chain termination via hydrogenation can occur at any point but is only shown explicitly for $\mathrm{C}_{2} \mathrm{H}_{x}$. Experimental proof for $\mathrm{CO}$-induced propylidyne and 1-butylidyne formation can be found in ref. $32 \star$

alkylidynes feasible intermediates for chain growth under FTS conditions.

Our experiments moreover show that $\mathrm{CO}$ spectators stabilize alkylidyne over all other forms of $\mathrm{C}_{x} \mathrm{H}_{y \text { ad }}$ and that alkylidynes are highly reactive in $\mathrm{C}-\mathrm{C}$ bond-forming reactions. These findings provide compelling support for the previously proposed alkylidyne chain growth mechanism ${ }^{4,38}$, schematically depicted in Fig. 8. New chains are initiated by coupling of two methylidyne $(\mathrm{CH})$ monomers, the most stable form of $\mathrm{CH}_{x a d}$, both without $^{31,48,49}$ and with CO co-adsorbed ${ }^{41}$. Subsequent, COpromoted hydrogenation of acetylene produces the ethylidyne needed for further growth. With the $\mathrm{C}_{1} \mathrm{H}_{x}$ concentration being much higher than that of growing chains under FTS conditions ${ }^{6,8}$, methylidyne insertion (producing adsorbed propyne) prevails over coupling with ethylidyne that we find in our model experiments. In analogy to the acetylene-ethylidyne reaction, $\mathrm{CO}$ also promotes conversion of the propyne coupling product to the propylidyne form ${ }^{32}$ needed for further growth. Chain termination requires hydrogenation and is comparatively slow, as illustrated by the difficulty to hydrogenate 2-butyne in our experiments. The mechanism observed in our experiments is of the carbide type, and although CO is promoting chain growth by stabilizing the intermediates in the correct form, it does not participate in the $\mathrm{C}-\mathrm{C}$ bond-forming reaction. A detailed analysis of the O1s spectra provided in Supplementary Note 8 shows that the formation of oxygen-containing intermediates during the experiments can be excluded.

The experimentally observed surface reactions presented here show that $\mathrm{C}-\mathrm{C}$ bond formation via alkylidyne coupling is favourable on the close-packed terraces that constitute $\sim 60 \%$ of the surface of an (fcc-)Co nanoparticle ${ }^{4,41}$. The methylidyne monomers required for chain growth during FTS can either be supplied via $\mathrm{H}$-assisted routes on the terrace or via spill-over from adjacent step sites that are active for $\mathrm{CO}$ dissociation ${ }^{18,50}$ and surround the nm-sized close-packed terrace exposed by an fcc-Co nanoparticle ${ }^{4}$. An fcc-Co nanoparticle also exposes (100) facets as well as step and kink sites ${ }^{51}$, and the role of the different structural elements remains a topic of debate ${ }^{52}$. Given that our experiments only speak about $\mathrm{C}_{x} \mathrm{H}_{y}$ reactivity on close-packed terraces, we can only provide a qualitative consideration about chain growth on other sites. Since the relative stabilities of $\mathrm{C}_{x} \mathrm{H}_{y}$ adsorbates depends on the surface structure, chain growth may proceed via a different pathway on other parts of the catalyst surface. In fact, experiments on stepped $\mathrm{Ni}(111)$ show that step sites favour $\mathrm{C}-\mathrm{C}$ bond scission rather than $\mathrm{C}-\mathrm{C}$ bond formation ${ }^{53,54}$, and $\mathrm{C}-\mathrm{C}$ bond scission was reported on $\mathrm{Ni}(100)$ at temperatures below $300 \mathrm{~K}^{55}$. This is in line with computational work on cobalt, which shows that $2 \mathrm{C}_{1} \mathrm{H}_{x}$ adsorbates are more stable than $\mathrm{C}_{2} \mathrm{H}_{x}$ adsorbates on both $\mathrm{Co}(100)$ and stepped $\mathrm{Co}$ (211), while acetylene and ethylidyne are instead significantly more stable than $2 \mathrm{CH}$ species on $\mathrm{Co}(111)^{41}$. In other words, C-C bond scission is favoured on steps and (100) facets, whereas C-C bond formation is favoured on terrace sites. This means that growth of long chains at step edges can only occur when exothermic C-C bond breaking is strongly suppressed, e.g. by a local high coverage at the step site. The concentration of carbon is indeed expected to be high on step sites due to their high affinity for carbon ${ }^{41,56}$. Chain growth requires growing chains to physically meet with a monomer, and since the growing chain concentration is expected to be small ${ }^{6}$, the nearest monomer is most probably generated at some distance from the growth intermediate. A high local coverage at step edges poses a significant barrier for $\mathrm{C}_{x} \mathrm{H}_{y}$ diffusion along the one-dimensional step edge, making it difficult for a monomer to reach a growing chain that is located a few sites away. Thus, owing to the limited mobility along the highly covered step sites, only those monomers formed at a small ensemble of step sites will contribute to a single chain, whereas monomers produced at step sites far away may not be able to reach the growing chain and make methane instead. Instead, spill-over of monomers to the adjacent (two-dimensional) terrace circumvents blockages of strongly adsorbed species at step sites so that monomers and growing chains can more easily diffuse over a larger distance and monomers produced by different active sites located at the edges of a single terrace can all be incorporated into the same product chain.

In summary, our detailed investigation of the reactivity of $\mathrm{C}_{2} \mathrm{H}_{x a d}$ species on $\mathrm{Co}(0001)$, both at low and near-ambient reactant pressures, reveals that a high coverage of $\mathrm{CO}_{\mathrm{ad}}$ spectators profoundly influences the reactivity of hydrocarbon adsorbates. CO-induced hydrogenation of adsorbed acetylene-producing ethylidyne $\left(\equiv \mathrm{C}-\mathrm{CH}_{3}\right)$ is a facile reaction that occurs around $270 \mathrm{~K}$. The driving force for the reaction is provided by a combination of $\mathrm{CO}$-induced destabilization of the $\mathrm{H}_{\text {ad }}$ reactant and stabilization of the ethylidyne product. Formation of 2-butyne $\left(\mathrm{H}_{3} \mathrm{C}-\mathrm{C} \equiv \mathrm{C}-\mathrm{CH}_{3}\right)$ occurs around $310 \mathrm{~K}$ via ethylidyne dimerization and highlights the high reactivity of alkylidynes $\left(\equiv \mathrm{C}-\mathrm{CH}_{2} \mathrm{R}\right)$ for $\mathrm{C}-\mathrm{C}$ bond formation on the close-packed surface of cobalt. The finding that $\mathrm{CO}_{a d}$ stabilizes $\mathrm{C}_{x} \mathrm{H}_{y \text { ad }}$ adsorbates in the alkylidyne form, which readily forms a new $\mathrm{C}-\mathrm{C}$ bond with other alkylidynes, rationalizes why $\mathrm{CO}$ promotes ethylene dimerization on cobalt catalysts. For FTS, we propose that C-C bonds form on the close-packed facets via coupling of a long-chain alkylidyne with a methylidyne monomer to form a 1-alkyne adsorbate. $\mathrm{CO}$ spectators promote chain growth by stabilizing the growing chain in the alkylidyne form needed for C-C bond formation. NAP-XPS shows that 2-butyne hydrogenation is slow. This suggest that the alkyne and alkylidyne adsorbates terminate only slowly, an essential requirement for the growth of long chains ${ }^{5}$.

\section{Methods}

Sample description and sample cleaning. The disc-shaped $(d=8 \mathrm{~mm}) \operatorname{Co}(0001)$ single crystal (Surface Preparation Laboratory) was cleaned by cycles of $\sim 10 \mathrm{~min}$ 
sputtering $\left(1 \mathrm{kV} \mathrm{Ar}{ }^{+}\right)$at $650 \mathrm{~K}$ followed by $\sim 10$ min annealing at the same temperature ${ }^{21,32}$. Residual carbon was most efficiently removed by dosing $\sim 1 \times$ $10^{-7} \mathrm{mbar} \mathrm{O}_{2}$ at $650 \mathrm{~K}$ for a few minutes. The excess surface oxygen can be removed by a short sputtering step or by exposure to $\mathrm{H}_{2}\left(10^{-6}-10^{-5} \mathrm{mbar}\right)$ at 650 $\mathrm{K}$. In this way, the carbon concentration could be reduced to below the sensitivity of synchrotron XPS.

Synchrotron XPS at ultra-high vacuum (UHV) condition. The synchrotron XPS measurements under UHV conditions reported here were performed at the SuperESCA beamline of ELETTRA, the European synchrotron light source located in Trieste, Italy ${ }^{57}$. For these experiments, the sample was spotwelded to a Ta rod, which was in direct thermal contact with a liquid nitrogen reservoir such that a sample temperature of $80 \mathrm{~K}$ could be reached. The sample was heated by the radiation of three tungsten filaments located close to its backside. Sample temperatures were measured using a $K$-type thermocouple, spotwelded to the side of the sample. Binding energies are reported relative to the Fermi edge, which was remeasured after each change of the photon energy. CO (SIAD, 99.95\%), propene (Messer, 99.5\%) and ethylene (SIAD, 99.995\%) were used without further purification during the experiments at the SuperESCA beamline. XPS did not show any indication of contaminations introduced by dosing these gases. The ordered layer formed by $\mathrm{CO}$ after adsorption at room temperature, with a coverage of 0.33 ML and a $(\sqrt{3} \times \sqrt{ } 3) \mathrm{R} 30^{\circ}$ in LEED, was used as a reference point for both C1s and $\mathrm{O} 1 s$ quantification ${ }^{21,25}$. C1s and O1s spectra were recorded with 800 and $1100 \mathrm{eV}$ for this known structure, where the higher photon energies were chosen to minimize the impact of photoelectron diffraction effects (Supplementary Note 2) on the signal intensity. The concentration of $\mathrm{C}_{x} \mathrm{H}_{y}$ species derived from XPS was found to be in good agreement with the values derived from TPRS, as discussed hereafter.

Synchrotron XPS at near-ambient conditions. The NAP XPS measurements were performed at the HIPPIE beamline of MAX IV, Lund, Sweden. The system consists of multiple chambers separated by gate valves. For the results presented here, only the preparation chamber, the transfer chamber (both with a base pressure of $\sim 5 x$ $10^{-10} \mathrm{mbar}$ ) and the analysis chamber (base pressure $\sim 5 \times 10^{-9} \mathrm{mbar}$ ) were used. Several sputter-anneal cycles $(1 \mathrm{keV} \mathrm{Ar}+)$ at $650 \mathrm{~K}$ combined with oxygen treatments $\left(p_{\mathrm{O} 2} \sim 1 \times 10^{-7} \mathrm{mbar}, 5 \mathrm{~min}\right.$ at $\left.650 \mathrm{~K}\right)$ were performed in the preparation chamber, where the sample can be heated by radiative or e-beam heating using a $\mathrm{W}$ filament in close proximity to the backside of the sample plate. Sample heating in the analysis chamber is performed by irradiating the backside of the sample plate with a fibrecoupled infrared laser. After transfer to the analysis chamber (via the transfer chamber), the sample cleanliness was checked at a sample temperature of $650 \mathrm{~K}$. Residual carbon was removed by dosing $\mathrm{O}_{2}\left(p \leq 1 \times 10^{-7} \mathrm{mbar}\right)$ at $650 \mathrm{~K}$ until the $\mathrm{C} 1 \mathrm{~s}$ region showed a carbon-free surface. Excess $\mathrm{O}_{a d}$ was then removed by dosing $\mathrm{H}_{2}(p \leq$ $1 \times 10^{-5} \mathrm{mbar}$ ) at $650 \mathrm{~K}$. Both UHV and NAP XPS can be performed in the analysis chamber. During measurements, the sample surface is $\sim 0.3 \mathrm{~mm}$ away from the entrance of the differentially pumped Scienta HIPP3 electron energy analyser. After preparation in UHV conditions, the NAP cell, with a volume of $\sim 500 \mathrm{~mL}$, can be closed and local pressures up to $30 \mathrm{mbar}$ can be introduced while the pressure in the main chamber remains $<5 \times 10^{-5}$ mbar.

Two stainless steel strips were used to clamp the sample onto a stainless steel flag-style sample holder. The sample temperature was measured using a $K$-type thermocouple, spotwelded to the sample plate below the $\mathrm{Co}(0001)$ sample. A photon energy of $420 \mathrm{eV}$ was used to record $\mathrm{C} 1 s$ spectra during $\mathrm{H}_{2}$ exposure and heating in $\mathrm{H}_{2}$. Owing to the extremely high photon flux generated by MAX IV, acquisition of a single C1s spectrum, in the presence of $\mathrm{H}_{2}(\mathrm{~g})$, takes around $30 \mathrm{~s}$. Spectra recorded with $800 \mathrm{eV}$ of a CO-covered surface serve as a quantitative reference to determine the coverages of $\mathrm{C}_{x} \mathrm{H}_{y}$ and $\mathrm{CO}_{\mathrm{ad}}$.

Ethylene (AGA, 99.95) and $\mathrm{O}_{2}$ (AGA, 99.999\%) were only dosed at UHV pressures and used without further purification. The $\mathrm{H}_{2}$ (AGA 99.998\%) first passed over a Pall GLPSIPVMM4 filter followed by a cold trap held at liquid nitrogen temperature prior to entering the NAP cell via a mass flow controller (MKS GF120). The experiments described in the main text reveal a small contamination with $\mathrm{CO}$. This could be due to a residual contamination in the gas or instead from $\left(\mathrm{H}_{2}\right.$-induced) desorption from the walls of the gas dosing system or those of the vacuum chamber. A trace amount of sulfur was detected by XPS after prolonged exposure to $\mathrm{H}_{2}$.

TPRS, LEED and RAIRS in UHV. The TPRS, LEED and RAIRS experiments were performed in a separate UHV set-up with a base pressure of $\sim 5 \times 10^{-10} \mathrm{mbar}$. Here the sample was clamped between the two legs of a 0.5 -mm-thick U-shaped tungsten wire that is in thermal contact with a liquid nitrogen reservoir so that a sample temperature of $\sim 95 \mathrm{~K}$ can be reached. The sample was heated by passing a direct current through the $\mathrm{W}$ support wire, and the temperature was measured using a $K$-type thermocouple, spotwelded to the backside of the sample. During the TPRS experiments, the sample is placed $\sim 5 \mathrm{~mm}$ away from the 5 - $\mathrm{mm}$-wide aperture of the (separately pumped) mass spectrometer compartment. This arrangement effectively eliminates peaks due desorption from other parts of the sample holder during heating. The known $0.5 \mathrm{ML} \mathrm{H}_{\mathrm{ad}}$-covered surface $30,37,58$ was used to determine the quantity of $\mathrm{H}_{2}$ produced during $\mathrm{C}_{x} \mathrm{H}_{y}$ decomposition. Using the known $\mathrm{C} / \mathrm{H}$ ratio in the precursor molecule, this can be translated to ML coverages of $\mathrm{C}_{x} \mathrm{H}_{y}$. A mass balance was used to quantify molecular desorption of ethene: $\mathrm{H}_{2}$ desorption shows that $0.12 \mathrm{ML}$ decomposes during heating in vacuum. Decomposition is suppressed down to $0.02 \mathrm{ML}$ when the same $\mathrm{C}_{2} \mathrm{H}_{4}$ layer is heated in $\mathrm{CO}$. The difference between $\mathrm{C}_{2} \mathrm{H}_{4}$ desorption in vacuum and in $\mathrm{CO}$ must therefore be equal to $0.1 \mathrm{ML}$, and with this reference point other coverages could be determined.

Infrared absorption spectra were recorded using a Perkin Elmer Frontier spectrometer. After leaving the spectrometer, the ( $p$-polarized) light travels through a compartment with custom-made optics that focus the beam onto the $8 \mathrm{~mm}$ discshaped sample. The light enters the vacuum chamber through a $\mathrm{KBr}$ window and is reflected off the sample surface. The angle of incidence is $15^{\circ}$ with respect to the surface plane. After reflection, the light leaves the vacuum chamber through another $\mathrm{KBr}$ window after which it is focused onto a liquid nitrogen-cooled MCT detector All parts of the beam path that are at atmospheric pressure are flushed with dry $\mathrm{N}_{2}$ to eliminate signals from $\mathrm{CO}_{2}(\mathrm{~g})$ and $\mathrm{H}_{2} \mathrm{O}(\mathrm{g})$ from the spectra. The spectrum obtained by reflection from a clean $\mathrm{Co}(0001)$ sample was subtracted from all spectra shown here, and in addition to this, a spline background was used to eliminate changes of the background resulting from sample heating. All spectra were measured with a resolution of $4 \mathrm{~cm}^{-1}$ and a step size of $0.5 \mathrm{~cm}^{-1}$. Thirty scans were averaged for each point in the TP-RAIRS experiments (Fig. 3a). The high-quality spectra shown in Fig. $3 \mathrm{~b}$ are the result of averaging 512 individual scans, recorded at $95 \mathrm{~K}$ to minimize thermal broadening. By removing the $\mathrm{CO}$ pressure at the annealing temperature ensures that the $\mathrm{CO}$ coverage and site occupation for the high-quality spectra is identical to the coverage at the annealing temperature. We found that the intensity of the absorption peak due to the symmetric $\mathrm{C}-\mathrm{H}$ bending mode of $-\mathrm{CH}_{3}$ in adsorbed 2-butyne, at $1365 \mathrm{~cm}^{-1}$, is very low. Since it appeared that cooling in $\mathrm{CO}$ led to a somewhat higher intensity of this band, we show the spectrum after cooling in $\mathrm{CO}$ in Fig. $2 \mathrm{~b}$ instead of the cooling in vacuum spectrum where the $1365 \mathrm{~cm}^{-1}$ band is more difficult to distinguish from the noise.

A liquid nitrogen trap was used to further purify the CO (CK Specialty Gases Ltd., 99.97\%) and $\mathrm{H}_{2}$ (CK Specialty Gases Ltd., 99.999\%) used during the TPRS, LEED and RAIRS experiments. Ethylene (Messer, 99.95\%) was used without further purification. 2-Butyne (Sigma-Aldrich, 99\%) used in reference experiments was degassed by several pump-freeze-thaw cycles prior to use.

\section{Data availability}

The data that support the findings of this study are available within the paper and its Supplementary Information, and all data are available from the authors on reasonable request.

Received: 15 August 2019; Accepted: 13 January 2020; Published online: 06 February 2020

\section{References}

1. van de Loosdrecht, J. et al. in Comprehensive Inorganic Chemistry II: From Elements to Applications (eds Reedijk, J. \& Poeppelmeier, K.) 525-557 (Elsevier Ltd., 2013).

2. Schlögl, R. Chemistry's role in regenerative energy. Angew. Chem. Int. 50, 6424-6426 (2011).

3. Claeys, M. \& van Steen, E. Basic studies. Stud. Surf. Sci. Catal. 152, 601-680 (2004).

4. Weststrate, C. J., van Helden, P. \& Niemantsverdriet, J. W. Reflections on the Fischer-Tropsch synthesis: mechanistic issues from a surface science perspective. Catal. Today 275, 100-110 (2016).

5. Van Santen, R. A., Ciobîcâ, I. M., Van Steen, E. \& Ghouri, M. M. Mechanistic issues in Fischer-Tropsch. Catal. Adv. Catal. 54, 127-187 (2011).

6. Mims, C. A., Krajewski, J. J., Rose, K. D. \& Melchior, M. T. Residence times and coverage by surface intermediates. Catal. Lett. 7, 119-125 (1990).

7. Mims, C. A. \& McCandlish, L. E. Evidence for rapid chain growth. J. Phys. Chem. 91, 929-937 (1987).

8. Bertole, C. J., Kiss, G. \& Mims, C. A. The effect of surface-active carbon on hydrocarbon selectivity in the cobalt-catalyzed Fischer-Tropsch synthesis. J. Catal. 223, 309-318 (2004).

9. Chen, W., Filot, I. A. W., Pestman, R. \& Hensen, E. J. M. Mechanism of cobalt-catalyzed CO hydrogenation: 2 . Fischer-Tropsch synthesis. ACS Catal. 7, 8061-8071 (2017).

10. Den Breejen, J. P. et al. On the origin of the cobalt particle size effects in Fischer-Tropsch catalysis. J. Am. Chem. Soc. 131, 7197-7203 (2009).

11. Navarro, V., van Spronsen, M. A. \& Frenken, J. W. M. In situ observation of self-assembled hydrocarbon Fischer-Tropsch products on a cobalt catalyst. Nat. Chem. 8, 929 (2016)

12. Paredes-Nunez, A. et al. Nature and reactivity of the surface species observed over a supported cobalt catalyst under $\mathrm{CO} / \mathrm{H}_{2}$ mixtures. Catal. Today 242, $178-183$ (2015).

13. Xu, L. et al. Water adsorption on a Co (0001) surface. J. Phys. Chem. C 114, 17023-17029 (2010) 
14. Bezemer, G. L. et al. Cobalt particle size effects in the Fischer-Tropsch reaction studied with carbon nanofiber supported catalysts. J. Am. Chem. Soc. 128, 3956-3964 (2006).

15. Geerlings, J. J. C., Zonnevylle, M. C. \& de Groot, C. P. M. Studies of the Fischer-Tropsch reaction on Co(0001). Surf. Sci. 241, 302-314 (1991).

16. Geerlings, J. J. C., Zonnevylle, M. C. \& de Groot, C. P. M. Structure sensitivity of the Fischer-Tropsch reaction on cobalt single crystals. Surf. Sci. 241, 315-324 (1991).

17. Ehrensperger, M. \& Wintterlin, J. In situ scanning tunneling microscopy of the poisoning of a $\mathrm{Co}(0001)$ Fischer-Tropsch model catalyst by sulfur. $J$. Catal. 329, 49-56 (2015).

18. Böller, B., Durner, K. M. \& Wintterlin, J. The active sites of a working Fischer-Tropsch catalyst revealed by operando scanning tunnelling microscopy. Nat. Catal. https://doi.org/10.1038/s41929-019-0360-1 (2019).

19. Andersen, J. N. et al. Vibrational fine structure in the $\mathrm{C} 1 \mathrm{~s}$ core level photoemission of chemisorbed molecules: ethylene and ethylidyne on $\mathrm{Rh}$ (111). Chem. Phys. Lett. 269, 371-377 (1997).

20. Steinrück, H. P., Fuhrmann, T., Papp, C., Tränkenschuh, B. \& Denecke, R. A detailed analysis of vibrational excitations in x-ray photoelectron spectra of adsorbed small hydrocarbons. J. Chem. Phys. 125, 204706 (2006).

21. Weststrate, C. J., Ciobîcă, I. M., van de Loosdrecht, J. \& Niemantsverdriet, J. W. Adsorption and decomposition of ethene and propene on $\operatorname{Co}(0001)$ : the surface chemistry of Fischer-Tropsch chain growth intermediates. J. Phys. Chem. C 120, 29210-29224 (2016).

22. Lorenz, M. P. et al. Ethene adsorption and dehydrogenation on clean and oxygen precovered $\mathrm{Ni}(111)$ studied by high resolution $\mathrm{x}$-ray photoelectron spectroscopy. J. Chem. Phys. 133, 11-16 (2010).

23. Borg, A. et al. Acetylene chemisorption and decomposition on the Co(11-20) single crystal surface. Surf. Sci. 499, 183-192 (2002).

24. Weststrate, C. J. et al. Atomic and polymeric carbon on $\mathrm{Co}(0001)$ : surface reconstruction, graphene formation, and catalyst poisoning. J. Phys. Chem. C 116, 11575-11583 (2012).

25. Weststrate, C. J., van de Loosdrecht, J. \& Niemantsverdriet, J. W. Spectroscopic insights into cobalt-catalyzed Fischer-Tropsch synthesis: a review of the carbon monoxide interaction with single crystalline surfaces of cobalt. J. Catal. 342, 1-16 (2016).

26. Wiklund, M., Beutler, A., Nyholm, R. \& Andersen, J. N. Vibrational analysis of the C 1 s photoemission spectra from pure ethylidyne and ethylidyne coadsorbed with carbon monoxide on Rh(111). Surf. Sci. 461, 107-117 (2000).

27. Weststrate, C. J. et al. Ethanol decomposition on $\mathrm{Co}(0001)$ : C-O bond scission on a close-packed cobalt surface. J. Phys. Chem. Lett. 1, 1767-1770 (2010).

28. Hirschmugl, C. J., Paolucci, G., Esch, F., Lizzit, S. \& Schindler, K.-M. Vibrational fine structure on $\mathrm{C} 1 s$ core-level photoemission: Ni(111)-ethyne and Ni(111)-butyne. Surf. Sci. 488, 43-51 (2001).

29. Vaari, J., Lahtinen, J. \& Hautojärvi, P. The adsorption and decomposition of acetylene on clean and K-covered Co(0001). Catal. Lett. 44, 43-49 (1997).

30. Habermehl-Ćwirzeń, K. M. E., Kauraala, K. \& Lahtinen, J. Hydrogen on cobalt: the effects of carbon monoxide and sulphur additives on the D2/Co (0001) system. Phys. Scr. T108, 28-32 (2004).

31. Weststrate, C. J. \& Niemantsverdriet, J. W. Understanding FTS selectivity: the crucial role of surface hydrogen. Faraday Discuss. 197, 101-116 (2016).

32. Weststrate, C. J. \& Niemantsverdriet, J. W. CO as a promoting spectator species of $\mathrm{CxHy}$ conversions relevant for Fischer-Tropsch chain growth on cobalt: evidence from temperature-programmed reaction and reflection absorption infrared spectroscopy. ACS Catal. 8, 10826-10835 (2018).

33. McCoustra, M. R. S., Ainsworth, M. K., De La Cruz, C., Chesters, M. A. \& Sheppard, N. An infrared study of ethene and CO coadsorption on $\mathrm{Pt}(111)$ and a $\mathrm{Pt} / \mathrm{SiO}_{2}$ catalyst: ambiguities in the interpretation of difference spectra. Surf. Sci. 437, 9-17 (2002).

34. Mims, C. A., Weisel, M. D., Hoffmann, F. M., Sinfelt, J. H. \& White, J. M. Site blocking effects in ethylidyne decomposition kinetics on $\mathrm{Ru}(001)$ : in-situ study with infrared reflection absorption spectroscopy at elevated pressure. $J$. Phys. Chem. 97, 12656-12659 (1993).

35. Zaera, F. An organometallic guide to the chemistry of hydrocarbon moieties on transition metal surfaces. Chem. Rev. 95, 2651-2693 (1995).

36. Blackman, G. S. et al. LEED and HREELS studies of the coadsorbed CO + ethylidyne and NO + ethylidyne systems on the Rh(111) crystal surface. Surf. Sci. 207, 66-88 (1988).

37. van Helden, P., van den Berg, J.-A. \& Weststrate, C. J. Hydrogen adsorption on Co surfaces: a density functional theory and temperature programmed desorption study. ACS Catal. 2, 1097-1107 (2012).

38. Weststrate, C. J., Ciobîcă, I. M., Saib, A. M., Moodley, D. J. \& Niemantsverdriet, J. W. Fundamental issues on practical Fischer-Tropsch catalysts: how surface science can help. Catal. Today 228, 106-112 (2014).

39. Zhang, M., Huang, H. \& Yu, Y. Insight into the mechanism of ethylene decomposition over $\mathrm{Co}(0001)$ surface: formation of carbon species. Catal. Lett. 149, 744-752 (2019).
40. Zhuo, M., Borgna, A. \& Saeys, M. Effect of the CO coverage on the FischerTropsch synthesis mechanism on cobalt catalysts. J. Catal. 297, 217-226 (2013).

41. van Helden, P. et al. Computational investigation of the kinetics and mechanism of the initial steps of the Fischer-Tropsch synthesis on cobalt. Faraday Discuss. 197, 117-151 (2017).

42. Mate, C. M., Kao, C.-T. \& Somorjai, G. A. Carbon monoxide induced ordering of adsorbates on the $\mathrm{Rh}(111)$ crystal surface: Importance of surface dipole moments. Surf. Sci. 206, 145-168 (1988).

43. Yang, Q. Y., Maynard, K. J., Johnson, A. D. \& Ceyer, S. T. The structure and chemistry of $\mathrm{CH}_{3}$ and $\mathrm{CH}$ radicals adsorbed on Ni(111). J. Chem. Phys. 102, 7734-7749 (1995).

44. Denecke, R. Surface chemistry studied by in situ X-ray photoelectron spectroscopy. Appl. Phys. A 80, 977-986 (2005).

45. Eidus, Y. T., Ershov, N. I., Zueva, T. V. \& Piroshkov, S. D. Accelerating effect of carbon monoxide as a function of its concentration and the reaction temperature during hydropolymerization of lower olefins. Bull. Acad. Sci. USSR Div. Chem. Sci. 23, 2758-2760 (1974).

46. Cant, N. W., Liu, I. O. Y. \& Scott, J. A. Ethylene oligomerisation over $\mathrm{Co} / \mathrm{SiO} 2$ in the presence of trace carbon monoxide: the Eidus reaction revisited. Catal. Today 215, 267-275 (2013).

47. Ormerod, R. M. \& Lambert, R. M. Critical ensemble required for acetylene cyclization on $\mathrm{Pd}(111)$ : a study of steric inhibition of coadsorbed oxygen. J. Phys. Chem. 16, 8111-8116 (1992).

48. Cheng, J. et al. A DFT study of the chain growth probability in FischerTropsch synthesis. J. Catal. 257, 221-228 (2008).

49. Liu, J. X., Su, H. Y. \& Li, W. X. Structure sensitivity of CO methanation on Co (0001), (10-12) and (11-20) surfaces: density functional theory calculations. Catal. Today 215, 36-42 (2013).

50. Weststrate, C. J., van Helden, P., van de Loosdrecht, J. \& Niemantsverdriet, J. W. Elementary steps in Fischer-Tropsch synthesis: CO bond scission, CO oxidation and surface carbiding on $\mathrm{Co}(0001)$. Surf. Sci. 648, 60-66 (2016)

51. van Helden, P., Ciobîcă, I. M. \& Coetzer, R. L. J. The size-dependent site composition of FCC cobalt nanocrystals. Catal. Today 261, 48-59 (2016).

52. Pestman, R., Chen, W. \& Hensen, E. Insight into the rate-determining step and active sites in the Fischer-Tropsch reaction over cobalt catalysts. ACS Catal. 9, 4189-4195 (2019).

53. Vang, R. T. et al. Controlling the catalytic bond-breaking selectivity of $\mathrm{Ni}$ surfaces by step blocking. Nat. Mater. 4, 160-162 (2005).

54. Vang, R. T. et al. Ethylene dissociation on flat and stepped Ni(111): a combined STM and DFT study. Surf. Sci. 600, 66-77 (2006).

55. Neubauer, R., Whelan, C. M., Denecke, R. \& Steinrück, H. P. The thermal chemistry of saturated layers of acetylene and ethylene on $\mathrm{Ni}(100)$ studied by in situ synchrotron x-ray photoelectron spectroscopy. J. Chem. Phys. 119, 1710-1718 (2003)

56. Zijlstra, B., Broos, R. J. P., Chen, W., Filot, I. A. W. \& Hensen, E. J. M. Firstprinciples based microkinetic modeling of transient kinetics of $\mathrm{CO}$ hydrogenation on cobalt catalysts. Catal. Today 342, 131-141 (2019).

57. Baraldi, A. et al. Time resolved core level photoemission experiments with synchrotron radiation. J. Electron Spectrosc. Relat. Phenom. 76, 145-149 (1995).

58. Huesges, Z. \& Christmann, K. Interaction of hydrogen with a cobalt $(0001)$ surface. Z. Phys. Chem. 227, 881-899 (2013).

\section{Acknowledgements}

This work has been carried out as part of the SynCat@DIFFER programme between the Dutch Institute for Fundamental Energy Research (DIFFER), Eindhoven university of Technology (TU/e) and Syngaschem BV and is funded jointly by the Netherlands Organization for Scientific Research (NWO) and Syngaschem BV (project number 731.016.301). We acknowledge ELETTRA, the European Synchrotron light source in Trieste, Italy (proposal 20180250), and MAX IV, the Swedish National Laboratory for research using X-rays, Lund, Sweden (proposal 20180237) for provision of beamtime. The staff at the SuperESCA (ELETTRA) and HIPPIE (MAX IV) beamlines are acknowledged for their excellent support. We acknowledge the technical support from the technical support staff at the DIFFER Institute. Professor Dr. M.C.M. van de Sanden (DIFFER) is acknowledged for commenting on the manuscript and providing valuable suggestions. Syngaschem BV gratefully acknowledges substantial funding from Synfuels China Technology Co. Ltd.

\section{Author contributions}

The experiments at the SuperESCA beamline of ELETTRA, Trieste were performed by D.S., D.G.R., M.A.G. and C.J.W. NAP-XPS measurements at the HIPPIE beamline of Max IV, Lund were performed by D.S., D.G.R., H.O.A.F. and C.J.W. TPRS, LEED and RAIRS experiments were performed by C.J.W. and supporting TPRS measurements were performed by D.S. The work was conceived and designed by C.J.W. who also wrote the principal draft of the paper with contributions from D.S., D.G.R., M.A.G. and H.O.A.F. followed by close review and editing by J.W.N. 


\section{Competing interests}

The authors declare no competing interests.

\section{Additional information}

Supplementary information is available for this paper at https://doi.org/10.1038/s41467020-14613-5

Correspondence and requests for materials should be addressed to C.-J.W.

Peer review information Nature Communications thanks the anonymous reviewers for their contribution to the peer review of this work. Peer reviewer reports are available.

Reprints and permission information is available at http://www.nature.com/reprints

Publisher's note Springer Nature remains neutral with regard to jurisdictional claims in published maps and institutional affiliations. (c) (i) Open Access This article is licensed under a Creative Commons Attribution 4.0 International License, which permits use, sharing, adaptation, distribution and reproduction in any medium or format, as long as you give appropriate credit to the original author(s) and the source, provide a link to the Creative Commons license, and indicate if changes were made. The images or other third party material in this article are included in the article's Creative Commons license, unless indicated otherwise in a credit line to the material. If material is not included in the article's Creative Commons license and your intended use is not permitted by statutory regulation or exceeds the permitted use, you will need to obtain permission directly from the copyright holder. To view a copy of this license, visit http://creativecommons.org/ licenses/by/4.0/.

(C) The Author(s) 2020 